\title{
Early mitochondrial alterations in ATRA-induced cell death
}

\author{
J Schmidt-Mende ${ }^{*, 1,2}$, V Gogvadze ${ }^{1}$, E Hellström-Lindberg ${ }^{2}$ and \\ B Zhivotovsky ${ }^{1}$ \\ ${ }^{1}$ Institute of Environmental Medicine, Division of Toxicology, Karolinska \\ Institutet, Box 210, Stockholm SE-171 77, Sweden \\ 2 Department of Medicine, Division of Hematology, Karolinska University \\ Hospital Huddinge, Stockholm SE-141 86, Sweden \\ * Corresponding author: J Schmidt-Mende, Institute of Environmental Medicine, \\ Division of Toxicology, Karolinska Institutet, Box 210, Stockholm SE-171 77, \\ Sweden. Tel: + 46 852487554; Fax: + 468 329041; \\ E-mail: Jan.Schmidt-Mende@ @medhs.ki.se
}

Received 18.3.05; revised 26.5.05; accepted 31.5.05; published online 08.7.05 Edited by R De Maria

\begin{abstract}
All-trans retinoic acid (ATRA) induces differentiation and subsequent apoptosis in a variety of cell lines. Using the myeloid cell line P39, we show that ATRA disturbs mitochondrial functional activity long before any detectable signs of apoptosis occur. These early changes include diminished mitochondrial oxygen consumption, decreased calcium uptake by mitochondria and as a result, a lower mitochondrial matrix calcium concentration. Granulocyte colony-stimulating factor (G-CSF) increases mitochondrial respiration and calcium accumulation capacity and subsequently blocks ATRA-induced apoptosis. Nifedipine, a plasma membrane calcium channel blocker, inhibits apoptosisrelated changes, such as the loss of the mitochondrial membrane potential and activation of caspases. Thus, the properties of ATRA and G-CSF to modulate mitochondrial respiration and intracellular calcium control are novel findings, which give insight into their precise molecular mode of action.
\end{abstract}

Cell Death and Differentiation (2006) 13, 119-128.

doi:10.1038/sj.cdd.4401715; published online 8 July 2005

Keywords: mitochondria; calcium; ATRA; differentiation; cell death

Abbreviations: APL, acute promyelocytic leukemia; ATRA, alltrans retinoic acid; CCCP, carbonyl cyanide $m$-chlorophenylhydrazone; ER, endoplasmic reticulum; G-CSF, granulocyte colony-stimulating factor; MDS, myelodysplastic syndromes; MPT, mitochondrial permeability transition; NBT, nitroblue-tetrazolium test; $\mathrm{RCR}$, respiratory control ratio; TMPD, tetramethylphenylenediamine; TMRE, tetramethylrhodamine

\section{Introduction}

All-trans retinoic acid (ATRA) is a natural derivative of vitamin $A$, which is successfully used in the treatment of acute promyelocytic leukemia (APL), where it induces terminal differentiation, and apoptosis of leukemic cells carrying the $15 ; 17$ translocation. ${ }^{1-4}$ We and others have shown that ATRA induces maturation followed by apoptosis in a variety of different cell lines. ${ }^{5-8}$ Differentiation induced by binding of ATRA to its nuclear retinoid receptors is detectable within $24-48 h^{9}$ followed by apoptosis at $72-96 h{ }^{5}$

It has been shown that mitochondria play an important regulatory role in ATRA-induced apoptosis. In this case, activation of proapoptotic Bcl-2 family proteins, such as Bid and $B a x$, results in permeabilization of the outer mitochondrial membrane and cytochrome $c$ release. ${ }^{10}$ ATRA was shown to downregulate the expression of the antiapoptotic protein $\mathrm{Bcl}-2,{ }^{11-13}$ which is known to inhibit cell death by interaction with proapoptotic Bcl-2 family members. However, in ATRAtreated cells, the initial triggering mechanism leading to the activation of Bid and Bax remains to be clarified. Using isolated rat liver mitochondria, it has been shown that ATRA can directly inhibit mitochondrial functioning, ${ }^{14,15}$ although the precise site of this interaction is unknown.

Granulocyte colony-stimulating factor (G-CSF) has been shown to inhibit mitochondria-mediated death in ATRAtreated myeloid cells. ${ }^{8}$ Furthermore, it reduces spontaneous apoptosis of neutrophils in vitro. ${ }^{16,17}$ In vivo, the clinical effects of G-CSF are also related to its antiapoptotic properties. It is routinely used to overcome neutropenia after chemotherapy, and to treat severe congenital neutropenia in Kostmann syndrome. ${ }^{18}$ In anemic patients with myelodysplastic syndromes (MDS), G-CSF and erythropoietin may synergistically improve hemoglobin levels and reduce marrow progenitor apoptosis. ${ }^{19-21}$ We have earlier shown that G-CSF decreases cytochrome $c$ release from mitochondria to cytosol, thereby reducing caspase activation and premature death of cultured MDS erythroblasts. ${ }^{22,23}$ However, the precise mode of the antiapoptotic action of G-CSF is still unclear.

Since calcium has been shown to enhance ATRA-induced differentiation, ${ }^{24,25}$ alterations in intracellular calcium regulation could be responsible for ATRA-induced apoptosis as well as for the observed rapid antiapoptotic effects of G-CSF. Calcium is an important cellular second messenger, which can regulate cell proliferation, ${ }^{26}$ mitochondrial function ${ }^{27}$ as well as differentiation ${ }^{28}$ and apoptosis. ${ }^{29}$ In our experiments, we investigated mitochondrial functional parameters, such as respiration and calcium uptake capacity, as well as different apoptosis-associated parameters (involvement of Bax, loss of $\Delta \Psi_{\mathrm{m}}$, release of cytochrome $c$ ) in the presence and/or absence of the growth factor G-CSF. Here, we show the importance of mitochondrial functioning and mitochondrial calcium regulation for ATRA-induced cell death. ATRA inhibits mitochondrial respiration and decreases mitochondrial capacity to accumulate calcium long before any signs of apoptosis occur. The importance of calcium in ATRA-induced cell death is supported by the fact that the calcium channel blocker Nifedipine can inhibit apoptosis. The growth factor G-CSF restores mitochondrial respiration and calcium accumulation 
capacity, and reduces apoptosis in ATRA-treated myeloid leukemia cells. The ability of G-CSF to influence mitochondrial oxidation and calcium uptake capacity is a novel important finding, which offers a new explanation for its antiapoptotic mode of action.

\section{Results}

\section{G-CSF inhibits ATRA-induced apoptosis}

Treatment of myelomonocytic $\mathrm{P} 39$ cells with ATRA resulted in differentiation after $24-48 \mathrm{~h}$ of incubation (data not shown) and apoptosis after $72 \mathrm{~h}$. At this time point, apoptosis was characterized by the release of cytochrome $c$ into the cytosol (Figure 2b), caspase activation and nuclear condensation (Figure 1a and b). Furthermore, ATRA induced timedependent disappearance of full-length Bid protein, and cleavage of another proapoptotic protein Bax (Figure 2a). Although a clear disappearance of full-length Bid was always observed in our experiments, we were not able to detect the
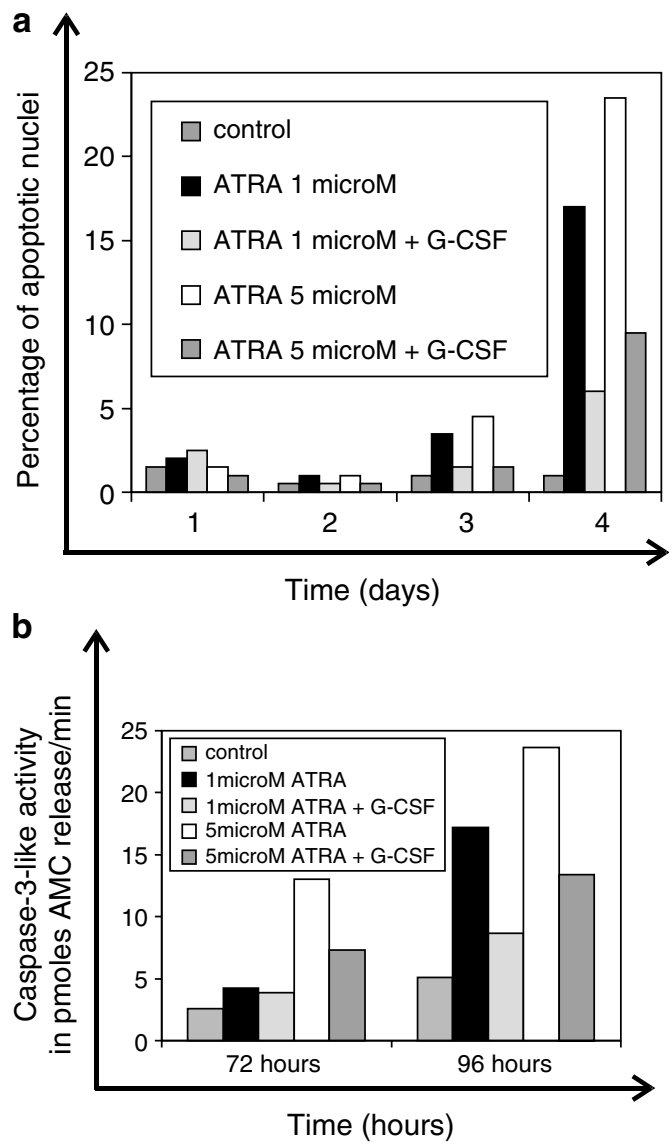

Figure 1 G-CSF inhibits ATRA-induced apoptosis. (a) ATRA induces apoptosis in P39 cells after 3 and 4 days of incubation. Cells were stained with May-Grünwald-Giemsa and the percentage of apoptotic cells was estimated by counting at least 200 cells. (b) ATRA induces caspase-3-like activity. Caspase-3-like activity was estimated by the cleavage of the fluorogenic substrate DEVD-AMC (see Materials and Methods). The amount of pmoles of AMC released per minute is shown. Representative data from one out of four independent experiments are shown cleavage product of this protein, tBid, as reported by another group. ${ }^{10} \mathrm{G}-\mathrm{CSF}$ was able to suppress all these manifestations of apoptosis. In addition to disappearance of the full-length Bid and cleavage of Bax, ATRA induced downregulation of antiapoptotic protein Bcl-2 started at day 1 and resulted in almost complete disappearance of the protein at day 3 (Figure 2a). Importantly, this downregulation of $\mathrm{Bcl}-2$ was not influenced by G-CSF. Similar downregulation of Bcl-2 was observed in ATRA-treated NB-4 cells (data not shown).

One of the earliest changes observed in ATRA-treated cells was a submaximal shift in the mitochondrial membrane potential $\left(\Delta \Psi_{\mathrm{m}}\right)$, which was detectable at day 1 (data not shown) and day 2 (Figure 2c). Later, at days 3 and 4 , a subpopulation of cells with completely collapsed $\Delta \Psi_{\mathrm{m}}$ appeared (Figure 2c (day 3 ) and d). This complete loss of $\Delta \Psi_{\mathrm{m}}$ was comparable with the loss of $\Delta \Psi_{\mathrm{m}}$ in cells treated with the mitochondrial uncoupler carbonyl cyanide $m$-chlorophenylhydrazone (CCCP) (data not shown). G-CSF but not z-VAD or calpain inhibitors markedly prevented the collapse of $\Delta \Psi_{\mathrm{m}}$ (Figure 3a). As mentioned above, G-CSF similarly inhibited cleavage of Bax. It has been shown that Bax can be cleaved either by caspases or calpain. ${ }^{30,31}$ However, under the conditions of our experiments, neither the pancaspase inhibitor z-VAD-fmk nor different calpain inhibitors such as E64d, PD150606 and calpeptin were able to prevent cleavage of Bax (Figure 3b).

\section{Effect of ATRA and G-CSF on mitochondrial oxygen consumption}

Mitochondria build up $\Delta \Psi_{\mathrm{m}}$ via oxidation of substrates in the mitochondrial respiratory chain. In order to understand the mechanism underlying early submaximal shift in $\Delta \Psi_{\mathrm{m}}$, the effect of ATRA on mitochondrial oxygen consumption was studied.

Experiments with isolated rat liver mitochondria revealed that ATRA decreased dose dependently state 3 respiration (measured as ADP-stimulated respiration), whereas state 4 respiration was dose dependently increased, indicating that ATRA partially uncouples mitochondria (Figure 4). Consequently, respiratory control ratio $(R C R)$ value was significantly decreased.

Inhibition of respiration has been shown to sensitize mitochondria to undergo calcium-induced MPT. ${ }^{32}$ As expected, ATRA-induced alteration of mitochondrial respiration resulted in deterioration of mitochondrial calcium retention capacity, which was assessed with a calcium-sensitive electrode (see Materials and Methods). ATRA (25 $\mu \mathrm{M})$ significantly accelerated spontaneous release of calcium from mitochondria (data not shown).

When P39 cells were cultured in the presence of ATRA $(5 \mu \mathrm{M})$ for $48 \mathrm{~h}$, ATRA significantly decreased oxygen consumption of these cells (Figure 5a). To investigate in detail which respiration complexes were specifically affected, ATRA-treated cells were permeabilized with low concentrations of digitonin as described in Materials and Methods and diverse mitochondrial respiratory substrates were provided. Pyruvate plus malate were used as substrates of complex I, succinate in the presence of rotenone for complex II and 
ascorbate with tetramethylphenylenediamine (TMPD) for complex IV. ATRA induced inhibition of mitochondrial respiration, which was documented already at day 1 and became significant at day 2 (Figure $5 b$ and c). State 3 , state 4 and uncoupled respiration in ATRA-treated cells were decreased, suggesting that the mitochondrial function was generally compromised by ATRA (Figure 5b). Importantly,

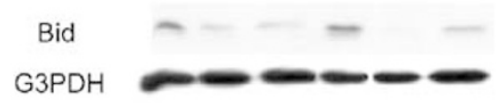

Bax

G3PDH

$\mathrm{Bcl}-2$

G3PDH

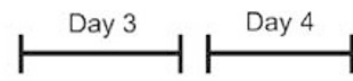

ATRA

G-CSF

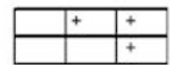

p18

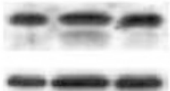

b

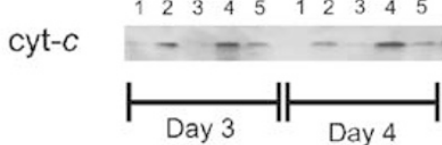

C

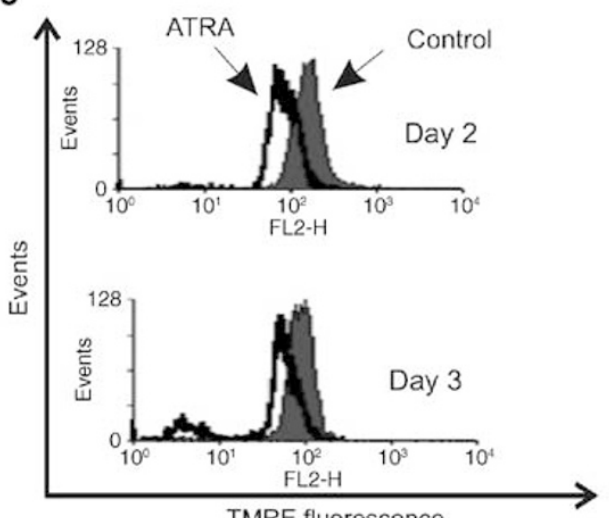

d

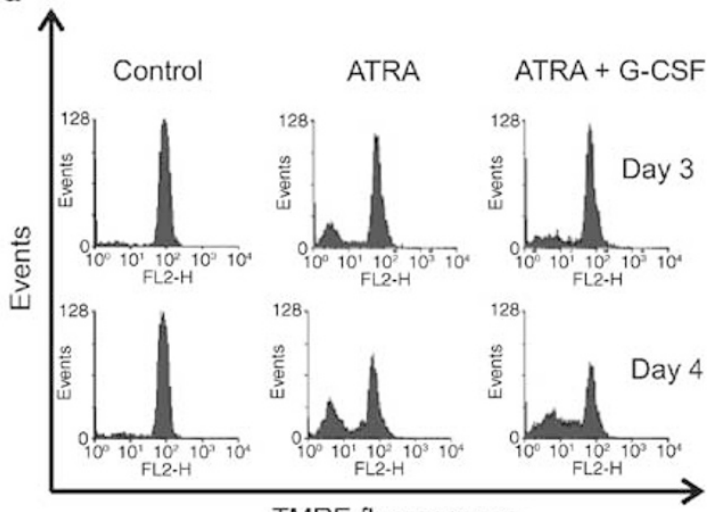

TMRE fluorescence coincubation with G-CSF markedly restored mitochondrial respiration both in intact and permeabilized cells. Restoration of respiration was observed with all substrates and under all states of respiration (state 3 , state 4 as well as CCCP-

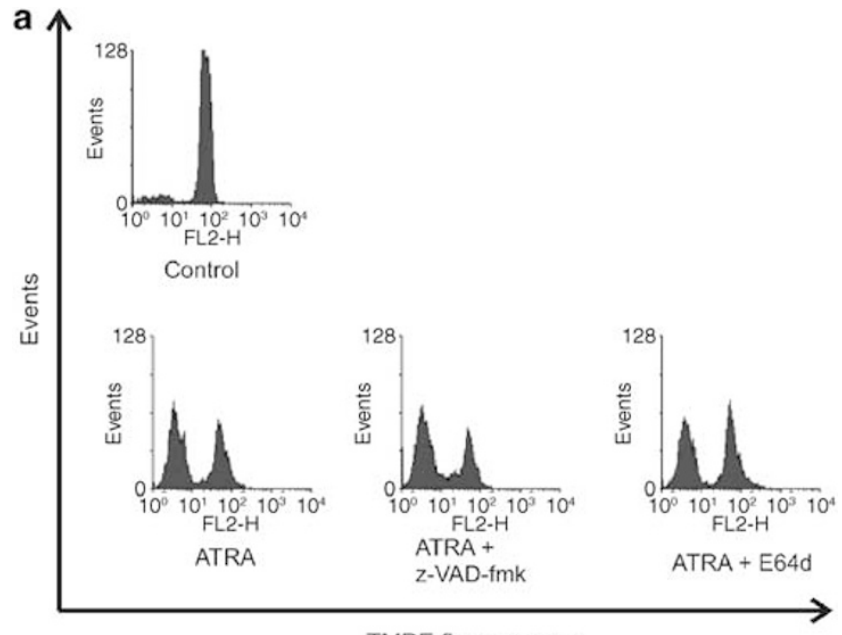

TMRE fluorescence

b

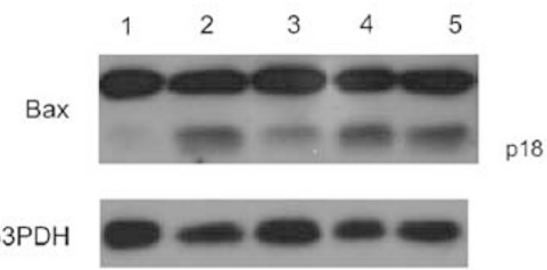

Figure 3 z-VAD-fmk and the calpain inhibitor E64d do not inhibit mitochondrial changes in ATRA-induced $(5 \mu \mathrm{M})$ apoptosis. (a) Cells were harvested after 4 days in culture and stained for 30 min with TMRE at $37^{\circ} \mathrm{C}$ and analyzed by FACS cytometry. Decrease in FL-2 fluorescence correlates with a decrease of the mitochondrial membrane potential. (b) Bax cleavage cannot be blocked by calpain or caspase inhibitors. Cells were harvested after 4 days in culture and Bax protein expression was investigated by Western blot. Loading was controlled by staining of membranes with Abs against G3PDH. Lane 1: control; lane 2: $5 \mu \mathrm{M}$ ATRA; lane 3: $5 \mu \mathrm{M}$ ATRA + G-CSF; lane 4: $5 \mu \mathrm{M}$ ATRA + $10 \mu \mathrm{M}$ z-VAD-fmk; lane 5: $5 \mu \mathrm{M}$ ATRA $+25 \mu \mathrm{M}$ E64d. Representative data from one out of four independent experiments are shown

Figure 2 Involvement of mitochondria in ATRA-induced apoptosis. (a) Downregulation of Bcl-2, disappearance of full-length Bid and cleavage of Bax upon treatment with ATRA $(5 \mu \mathrm{M})$. Bax cleavage and disappearance of fulllength Bid can be blocked by G-CSF. Cells were harvested at the indicated time points and the expression of proteins of interest was investigated by Western blot. Loading was controlled by staining of the membranes with Abs against G3PDH. (b) ATRA induces and G-CSF prevents cytochrome $c$ release. Cytosolic extracts were prepared at days 3 and 4 as described in Materials and Methods. Lane 1: control; lane 2: $1 \mu \mathrm{M}$ ATRA; lane 3: $1 \mu \mathrm{M}$ ATRA + G-CSF; lane 4: $5 \mu \mathrm{M}$ ATRA; lane 5: $5 \mu \mathrm{M}$ ATRA + G-CSF. (c) Submaximal shift of the mitochondrial membrane potential in ATRA-treated $(5 \mu \mathrm{M})$ cells compared to control cells. Cells were harvested and stained for $30 \mathrm{~min}$ with TMRE at $37^{\circ} \mathrm{C}$ and analyzed by FACS. Decrease in FL-2 channel fluorescence correlates with a decrease of the mitochondrial membrane potential. Overlay histograms are shown after 2 and 3 days of treatment onset. (d) ATRA induces a drop of the mitochondrial membrane potential. Cells were harvested and stained for $30 \mathrm{~min}$ with TMRE at $37^{\circ} \mathrm{C}$ and analyzed by FACS. Decrease in FL-2 channel fluorescence correlates with a drop of the mitochondrial membrane potential after 3 and 4 days of treatment onset. Representative data from one out of four independent experiments are shown 

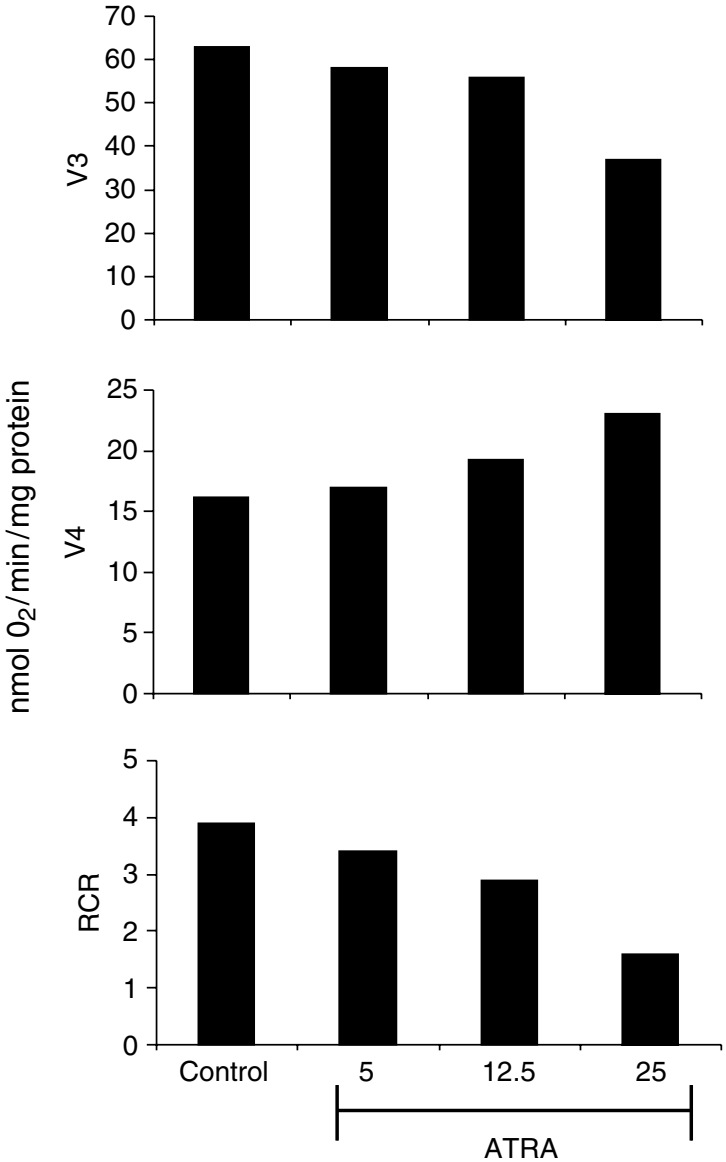

Figure 4 Effect of ATRA on oxygen consumption and RCR in isolated rat liver mitochondria. Rat liver mitochondria were isolated as described in Materials and Methods. Oxygen consumption in $\mathrm{nmol} / \mathrm{min} / \mathrm{mg}$ mitochondrial protein was estimated with an oxygen electrode after the addition of $5,12.5$ and $25 \mu \mathrm{M}$ ATRA. State 3 (V3; after the addition of ADP) and state 4 (V4) respiration were used to calculate RCR. Representative data from one out of three independent experiments are shown

stimulated respiration, Figure $5 \mathrm{a}-\mathrm{c}$ ). Similar early reduction of respiration upon ATRA treatment was observed in the APL cell line NB-4 (data not shown).

\section{G-CSF restores ATRA-induced reduction of mitochondrial calcium buffering capacity in cells}

In order to elucidate how decreased respiration could affect mitochondrial functioning, the ability of mitochondria to accumulate calcium in ATRA-treated cells was studied. The accumulation of calcium into mitochondria was assessed with a calcium-sensitive electrode. Cells were permeabilized as described in Materials and Methods and loaded with calcium pulses as shown in Figure 6a until mitochondrial permeability transition (MPT) occurred and all accumulated calcium was released. ATRA markedly reduced the ability of mitochondria to accumulate calcium and decreased the threshold level of calcium, which is necessary for MPT induction (Figure 6b). These changes were detected at early time points of incubation (days 1 and 2) when apoptosis had not yet occurred. G-CSF significantly restored mitochondrial calcium
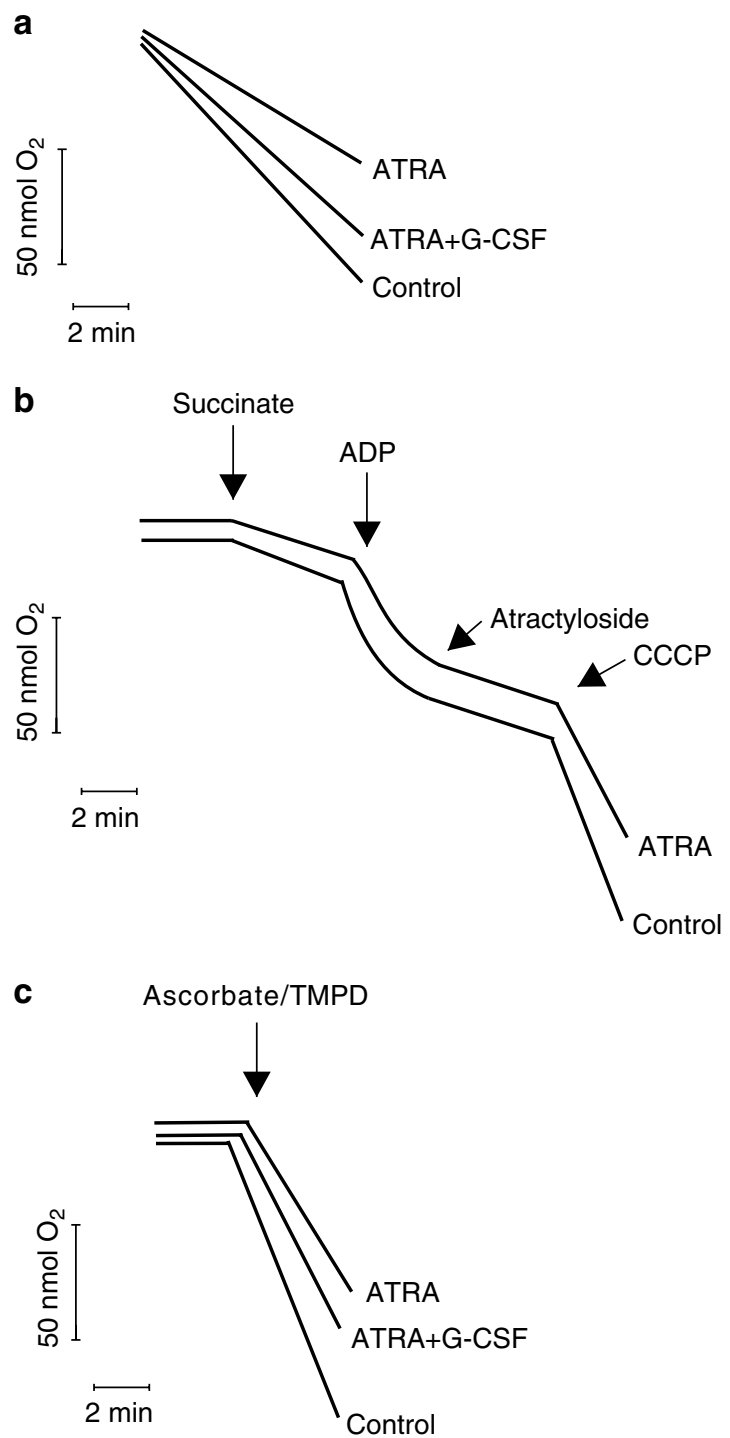

Figure 5 Effect of G-CSF on reduced oxygen consumption in permeabilized P39 cells after 2 days of incubation with $5 \mu$ M ATRA. (a) Oxygen consumption of nonpermeabilized cells kept in the standard medium. (b) Permeabilized cells in $\mathrm{KCl}$ buffer with succinate as electron donator in the presence of rotenone. $\mathrm{V} 3$ respiration was measured after the addition of ADP, V4 after the addition of atractyloside and uncoupled respiration after the addition of CCCP. (c) Permeabilized cell in $\mathrm{KCl}$ buffer, ascorbate/TMPD were used as electron donator. Representative data from one out of three independent experiments are shown

uptake (data not shown). A similar reduction of mitochondrial calcium accumulation capacity was observed in NB-4 cells upon ATRA treatment and occurred long before any signs of apoptosis were detected. In this cell line, G-CSF neither increased the mitochondrial calcium accumulation capacity nor suppressed apoptosis at later time points (data not shown).

Inhibition of mitochondrial calcium accumulation resulted in a decrease in mitochondrial matrix calcium content at day 2 (Figure $6 \mathrm{c}$ and d). G-CSF partially restored the reduced calcium ion concentration in the mitochondrial matrix. No measurements of calcium content at later time points (days 3 
and 4) were performed since it was obvious that due to the collapse in $\Delta \Psi_{\mathrm{m}}$, the calcium content would inevitably drop at these time points.

a

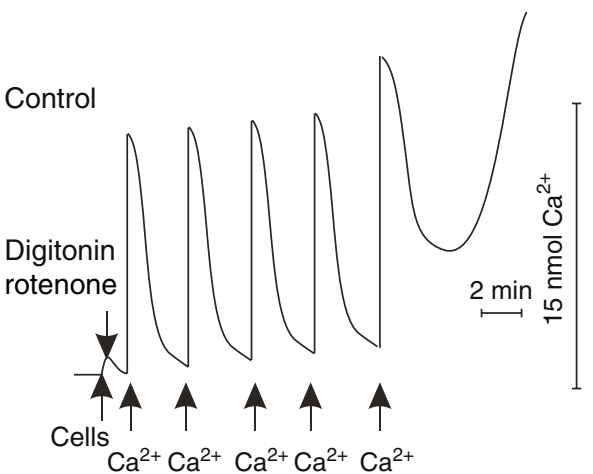

b

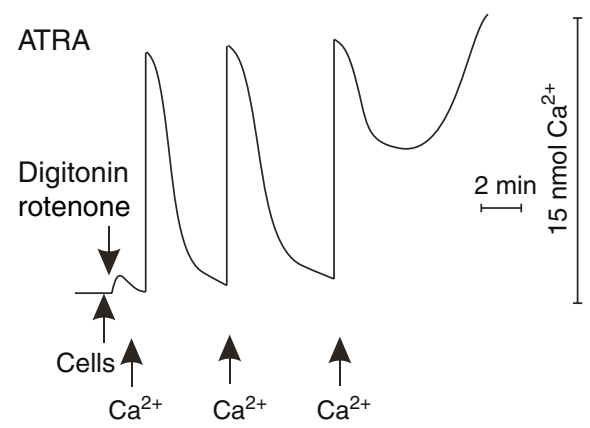

C

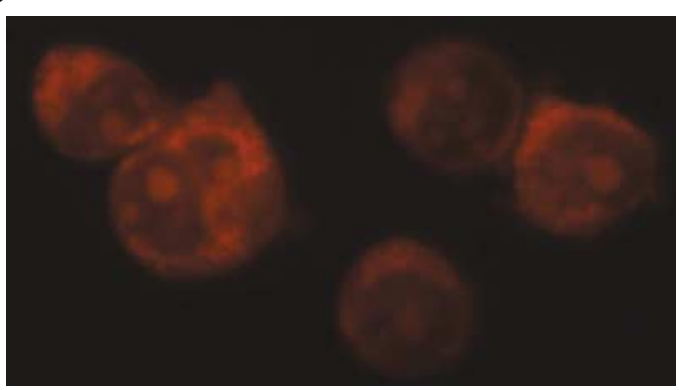

d

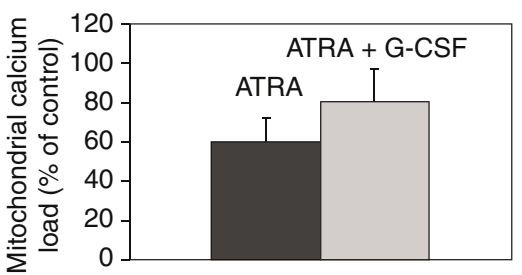

Figure 6 Reduced mitochondrial calcium uptake and mitochondrial calcium concentration in ATRA-treated cells $(5 \mu \mathrm{M})$ after 2 days of incubation (a and $\mathbf{b}$ ) Cells were permeabilized with digitonin and calcium uptake was measured with a calcium-sensitive electrode after addition of calcium into $\mathrm{KCl}$-based incubation buffer. Representative data from one out of four independent experiments are shown. (c) The cationic fluorescent calcium indicator dye Rhod-2 accumulates preferentially in mitochondria, since it is highly charged and therefore readily retained by the polarized mitochondria, which localize around the nucleus. Representative data from one out of five independent experiments are shown. (d) Measurement of mitochondrial calcium load by Rhod-2 fluorescence (shown as the percentage of control cell load). Mean and S.D. of five independent experiments are shown. For each experiment, mitochondrial calcium content of control cells was set as $100 \%$

\section{Nifedipine inhibits ATRA-induced apoptosis}

Mitochondrial deterioration observed in apoptotic cells are frequently caused by induction of calcium-dependent MPT as a result of a disturbed cytosolic calcium homeostasis. ${ }^{32}$ In order to test whether extracellular calcium is involved in ATRA-induced mitochondrial changes, cells were coincubated with Nifedipine, a plasma membrane calcium channel blocker. Nifedipine had no effect on ATRA-induced differentiation as determined by the nitroblue-tetrazolium test (NBT, data not shown). However, Nifedipine markedly prevented apoptosis and significantly suppressed appearance of its characteristic manifestations such as the collapse of $\Delta \Psi_{\mathrm{m}}$ (Figure 7a), cleavage of Bax (Figure $7 \mathrm{~b}$ ), activation of caspases, reactive oxygen species (ROS) production and the accumulation of condensed nuclei (data not shown). This inhibitory effect of Nifedipine was dose dependent and most prominent at $50 \mu \mathrm{M}$. The intracellular calcium chelator EGTAAM had similar effects, when it was used instead of Nifedipine (data not shown). In contrast to G-CSF, Nifedipine did not restore mitochondrial respiration decreased by ATRA. Moreover, it slightly decreased mitochondrial respiration by itself. In addition, Nifedipine markedly suppressed calcium accumula-

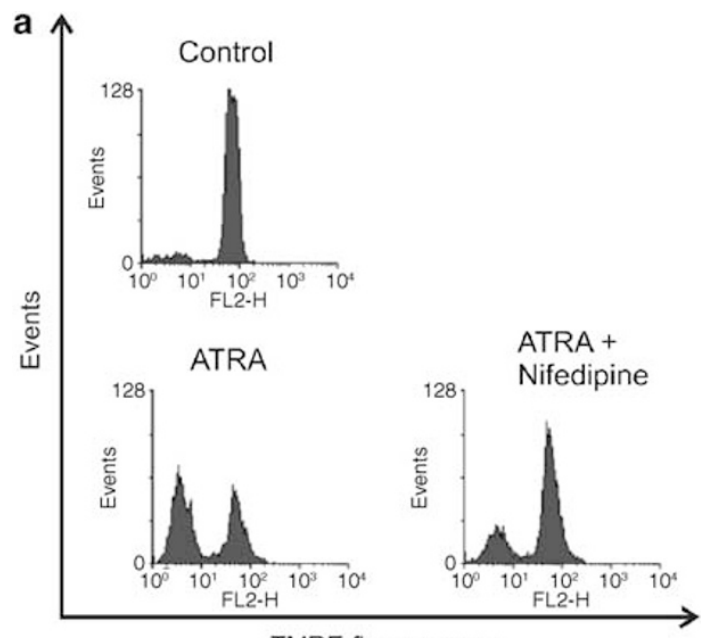

TMRE fluorescence

b

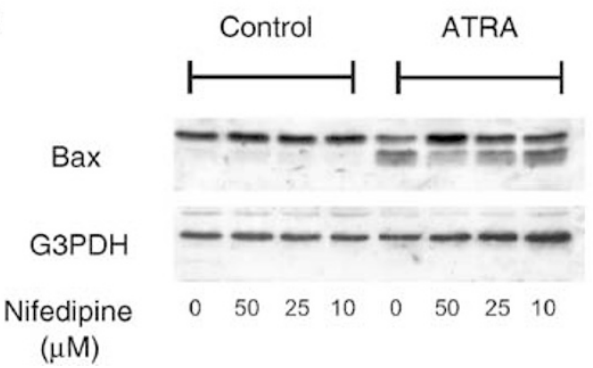

Figure 7 Nifedipine blocks mitochondrial changes in apoptotic cells after 3 days of incubation with ATRA $(5 \mu \mathrm{M})$. (a) Cells were harvested and stained for 30 min with TMRE at $37^{\circ} \mathrm{C}$ and analyzed by FACS cytometry. Decrease in FL-2 fluorescence correlates with a decrease of the mitochondrial membrane potential. (b) Bax cleavage. Cells were harvested and Bax protein expression was investigated by Western blot. G3PDH counterstaining was used as an equal loading control. Representative data from one out of four independent experiments are shown 
tion in mitochondria at $25 \mu \mathrm{M}$, the concentration that did not affect respiration (data not shown).

\section{ATRA does not induce early changes in the cytosolic calcium concentrations}

Since suppression of calcium channels by Nifedipine prevented ATRA-induced apoptosis, it was of interest to test whether ATRA affects cytosolic calcium concentration. Experiments using cells stained with Fluo-4 followed by FACS analysis revealed that at early time points (days 1 and 2; data not shown), no increase of cytosolic calcium concentrations was observed in the ATRA-treated cells. At late time points (days 3 and 4; Figure 8a), raise of intracellular calcium concentrations was detected, which occurred simultaneously with signs of apoptosis. After gating the apoptotic cell population by forward sideward scatter criteria, it became evident that calcium levels were increased in the apoptotic cells only (Figure 8b). As expected, Nifedipine blocked this late calcium increase (Figure 8c).

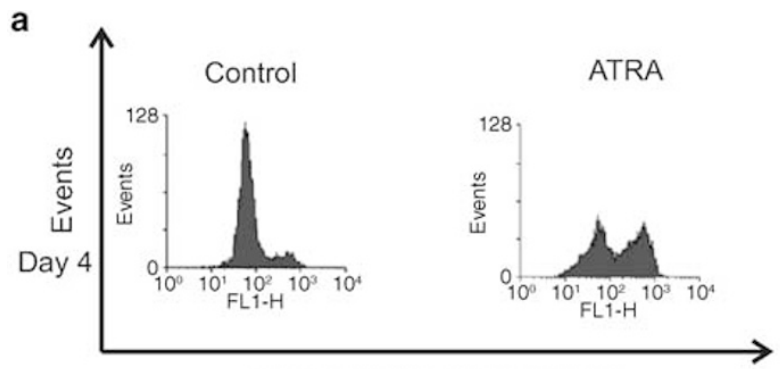

Increased Fluo-4 fluorescence

b

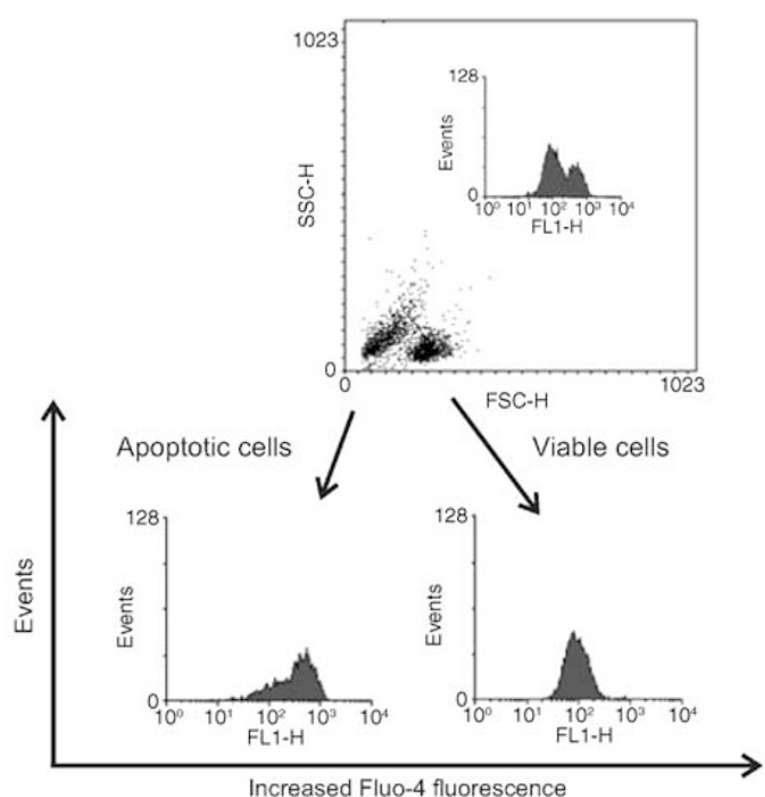

In order to prove that calcium is important for ATRA-induced apoptosis, we cocultured the cells with $100 \mathrm{nM}$ ATRA (a concentration that is more than 10-fold lower than the lowest usual concentration used) and thapsigargin $(5 \mathrm{nM})$, which blocks calcium accumulation into the endoplasmic reticulum (ER) and thereby stimulates the release of calcium from the ER. At these concentrations, ATRA or thapsigargin alone were unable to induce apoptosis. However, combination of both drugs evoked effects similar to those induced by high concentrations of ATRA (Figure 8d).

\section{Discussion}

It has been previously shown that ATRA induces cell death via targeting mitochondria. ${ }^{7}$ However, the precise mechanism of mitochondrial engagement in ATRA-induced apoptosis remains vague. In the present study, several parameters characterizing proper mitochondrial functioning (respiration and calcium buffering capacity) as well as parameters important for activation and execution of mitochondria-

c

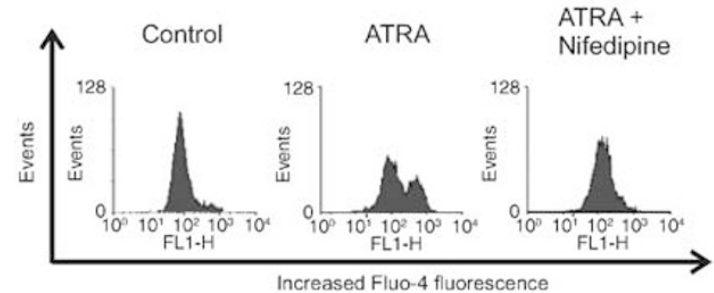

d

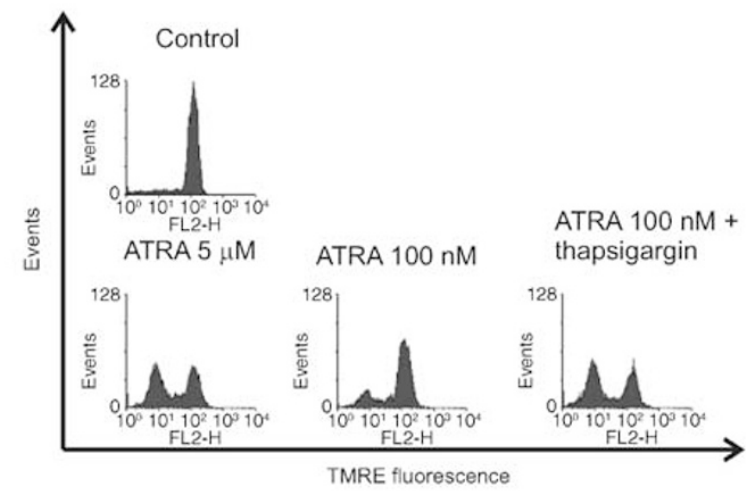

Figure 8 Significance of intracellular calcium for ATRA-induced apoptosis. (a) Increased calcium content in apoptotic cells after 4 days of ATRA treatment (5 $\mu$ M) measured by Fluo-4 fluorescence. (b) Gated apoptotic and nonapoptotic cell populations after 3 days of culture; calcium rises in apoptotic cells measured by Fluo-4 fluorescence. (c) Nifedipine inhibits apoptosis and the calcium rise in ATRA-treated cells after 3 days of culture as measured by Fluo-4 fluorescence. (d) Thapsigargin potentiates the effect of low-dose ATRA treatment. Cells were harvested after 4 days of culture and stained for 30 min with TMRE at $37^{\circ} \mathrm{C}$ and analyzed by FACS cytometry. Decrease in FL-2 fluorescence correlates with a drop of the mitochondrial membrane potential. Representative data from one out of three independent experiments are shown 
mediated killing (cleavage of the proapoptotic protein Bax, cytochrome $c$ release and drop of mitochondrial membrane potential) were studied in parallel. A clear link between early changes (24-48h) in mitochondrial functioning and the later apoptotic changes (72-96 h) was observed.

Mitochondria play a pivotal role in many models of apoptosis. Release of proteins such as cytochrome $c$ and/or AIF from the intermembrane space of mitochondria is a key event in initiation and/or propagation of apoptosis. ${ }^{33}$ We have previously demonstrated that cytochrome $c$ release can occur via distinct mechanisms that are either calcium dependent or independent. ${ }^{34}$ In one case, calcium promotes MPT due to opening of a nonspecific pore in the inner mitochondrial membrane. This results in mitochondrial swelling and a rupture of the outer mitochondrial membrane. In contrast, calcium-independent permeabilization of the outer mitochondrial membrane occurs due to insertion of proapoptotic proteins, such as Bax or Bak, in the outer membrane with the formation of a pore large enough for passing cytochrome c. Interestingly, according to our data, Bax not only forms pores in the outer membrane of mitochondria but also facilitates calcium-dependent MPT. Thus, we can conclude that release of cytochrome $c$, which starts $72 \mathrm{~h}$ after administration of ATRA, results from calcium-dependent MPT induction.

Indeed, ATRA-treated cells demonstrated inhibition of respiration, which was observed both in intact and digitoninpermeabilized cells (Figure 5). This inhibition resulted in a submaximal shift of $\Delta \Psi_{\mathrm{m}}$ (Figure 2c). It is known that a general decrease in the mitochondrial membrane potential is an important factor responsible for MPT. ${ }^{32}$ Despite a moderate magnitude of this shift, it caused a substantial decrease in the threshold level of calcium required for MPT induction (Figure 6b), when mitochondria in permeabilized cells were loaded with calcium. Recent experiments with isolated mitochondria showed that a partial suppression of mitochondria respiration by malonate markedly stimulated MPT induction. ${ }^{35}$ Generally, mitochondria displaying high $\Delta \Psi_{\mathrm{m}}$ can tolerate calcium fluctuations occurring during cell functioning. However, a suppression of mitochondrial respiration and consequent reduction of $\Delta \Psi_{\mathrm{m}}$ could be a factor stimulating MPT in a subpopulation of mitochondria, especially taking into consideration their heterogeneity. Starting at day 3 after treatment with ATRA, we observed a subpopulation of cells with $\Delta \Psi_{m}$ collapsed to the levels comparable to the uncoupler CCCP-induced drop (Figure 2d). Since it is known that downregulation of $\mathrm{Bcl}-2^{36}$ and cleavage of $\mathrm{Bax}^{37}$ sensitize mitochondria towards MPT induction, it is likely that ATRA-induced downregulation of Bcl-2, which started within $24 \mathrm{~h}$ upon ATRA treatment, and Bax cleavage, which occurred after $72 \mathrm{~h}$, contribute to sensitization of mitochondria towards MPT induction. This early $\mathrm{Bcl}-2$ downregulation upon ATRA treatment was also detected in promyelocytic NB-4 cells and preceded the onset of apoptotic features (data not shown).

Results presented here propose novel insights in the apoptosis inhibitory effects of G-CSF and the L-type calcium channel blocker Nifedipine. Even though both drugs blocked ATRA-induced apoptosis and did not decrease differentiation (determined by the NBT test), their mode of action was completely different. G-CSF restored mitochondrial respiration and normalized mitochondrial calcium accumulation capacity. G-CSF did not influence the expression levels of Bcl-2 when added to control or ATRA cultures (data not shown). Interestingly, in NB-4 cells opposite to P39 cells, GCSF did not prevent the early mitochondrial changes in respiration and calcium accumulation capacity and consequently did not block apoptosis at later time points. These results confirm the recent findings that in APL cell lines G-CSF facilitates differentiation and thereby stimulates the maturation and apoptosis program induced by ATRA. ${ }^{38,39}$

In contrast to GCSF, Nifedipine had no apparent effect on mitochondrial respiration. However, Nifedipine rendered protection of cells via blocking calcium channels, preventing flooding the cytosol with calcium and therefore decreasing the possibility for calcium-induced MPT. Similar results were obtained when the intracellular calcium chelator EGTA-AM was used in order to prevent fluctuations of calcium in the cytoplasm (data not shown). Additionally, the protective effect of Nifedipine against mitochondrial calcium overloading and hence MPT induction comes from the capability of Nifedipine to suppress mitochondrial calcium accumulation.

Further evidence of the involvement of calcium in ATRAinduced apoptosis was shown when noninducing apoptosis concentration of ATRA was administered to cells in the presence of thapsigargin, an inhibitor of calcium ATPase of ER. Thapsigargin stimulates release of calcium from ER and elevates cytosolic calcium concentration. Combined action of low concentration of ATRA and thapsigargin brought about the same effect as apoptosis-inducing high doses of ATRA (Figure 8d).

In addition, we also addressed the question whether ATRA has a direct effect on mitochondria (Figure 4). Incubation of ATRA with isolated rat liver mitochondria revealed a decrease in state 3 respiration, while state 4 respiration was increased. However, using permeabilized P39 cells, we did not observe a specific decrease in state 3 respiration after incubation with ATRA. This drug reduced mitochondrial function without any preference for any respiration states. Furthermore, direct effects on mitochondria required higher ATRA concentrations $(12.5$ and $25 \mu \mathrm{M})$, which cannot be reached in the cytosol, since ATRA binds to cytosolic retinoid-binding proteins. ${ }^{40}$ Thus, we concluded that a direct ATRA-mitochondria interaction might be relatively unlikely and the observed effects on mitochondrial function ${ }^{14,15}$ might not occur on cellular level.

In conclusion, both ATRA and G-CSF have significant influence on respiration as well as mitochondrial calcium accumulation (Figure 9). While the expression and activation of Bcl-2 family members in ATRA- and G-CSF-treated cells have been extensively studied by many groups, we, for the first time, observed early mitochondrial alterations and linked these early alterations to the late apoptotic events. Furthermore, we introduce intracellular calcium deregulation as a novel and significant mediator of ATRA-induced apoptosis. We believe that results obtained in this study are important for understanding the molecular mechanisms of G-CSF and ATRA action in more details. These results also provide new guidelines for risks and benefits in the clinical use of these drugs. 
nitrocellulose for $2 \mathrm{~h}$ at $100 \mathrm{~V}$. Membranes were blocked for $1 \mathrm{~h}$ with $5 \%$ nonfat milk in phosphate-buffered saline (PBS) at room temperature and subsequently probed overnight with primary antibody. The membranes were rinsed and incubated with a horseradish peroxidase-conjugated secondary antibody (1:10000). Following incubation with secondary antibody, membranes were rinsed and bound antibodies were detected using enhanced chemiluminescence according the manufacturer's instructions. For preparation of cytosolic extracts, cells were permeabilized with $0.005 \%$ digitonin and incubated for $5 \mathrm{~min}$ on ice in a buffer containing $150 \mathrm{mM} \mathrm{KCl}, 5 \mathrm{mM} \mathrm{KH}_{2} \mathrm{PO}_{4}, 1 \mathrm{mM} \mathrm{MgSO}{ }_{4}, 5 \mathrm{mM}$ succinate, $5 \mathrm{mM}$ Tris and $1 \mathrm{mM}$ EGTA at $\mathrm{pH}$ 7.4. Subsequently, whole-cell lysates or supernatant and pellet fractions were analyzed by SDS-PAGE followed by Western blotting using as a primary antibodies raised against cytochrome $c(1: 2500$, BD Pharmingen, BD Bioscience, San Diego, USA), Bax (1 : 1000, BD Pharmingen, BD Bioscience, San Diego, USA), Bid (1:1000, Cell Signaling Technology, Beverly, USA), Bcl-2 (1:100, Dako, Glostrup, Denmark) and G3PDH (1:2000, Nordic BioSite, Täby, Sweden).

\section{Measurements with fluorescent dyes}

accumulation capacity, decreased mitochondrial matrix calcium concentration, submaximal shift of $\Delta \psi_{\mathrm{m}}$
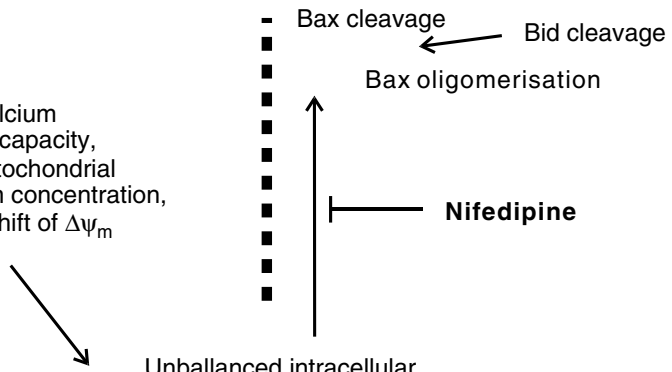

The mitochondrial transmembrane potential $\left(\Delta \Psi_{\mathrm{m}}\right)$ was measured using the cationic fluorescent dye tetramethylrhodamine ethyl ester (TMRE, final concentration $25 \mathrm{nM}$, Molecular Probes, Leiden, The Netherlands), which normally accumulates in mitochondria as a direct function of $\Delta \Psi_{\mathrm{m}}$. Changes in intracellular calcium concentrations were visualized by the dye Fluo-4-AM ( $5 \mu \mathrm{M}$, Molecular Probes, Leiden, The Netherlands). Rhod-2AM $(2.5 \mu \mathrm{M}$, MoBiTec, Göttingen, Germany) was used to assess intramitochondrial calcium.

Briefly, $5 \times 10^{5}$ (FACS measurements) or $4 \times 10^{6}$ (plate reader

Figure 9 Proposed sequence of ATRA-mediated early and late mitochondrial changes. Early ATRA-induced alterations are characterized by decreased mitochondrial respiration and calcium uptake capacity. Late changes are characterized by the activation of Bcl-2 family proteins, such as Bid and Bax, followed by cytochrome $c$ release from mitochondria. Finally, caspases are activated and apoptosis is executed. G-CSF and Nifedipine inhibit apoptosis, but their mode of action is different. G-CSF inhibits early mitochondrial changes, while Nifedipine influences calcium content in the cells

\section{Materials and Methods}

\section{Cell cultures}

The P39 cell line/Tsugane is a myelomonocytic cell line derived from the peripheral blood of a patient suffering from leukemia following MDS (kindly provided by Professor Y Yoshida, Center for South East Asian Studies, Kyoto University, Kyoto, Japan). P39 and NB-4 cells were seeded at a concentration of $0.25 \times 10^{6}$ cells/ml in RPMl 1640 (Sigma, Stockholm, Sweden) supplemented with $10 \%$ heat-inactivated fetal calf serum (FCS), penicillin and streptomycin (1\% in the medium) at $37^{\circ} \mathrm{C}$ in a humidified atmosphere containing $5 \% \mathrm{CO}_{2}$. Cells were used for the experiments in exponential growth phase. Cells were incubated with ATRA ( 1 and $5 \mu \mathrm{M}$, Sigma, Stockholm, Sweden) for up to $96 \mathrm{~h}$. G-CSF (Neupogen, Amgen, Stockholm, Sweden) concentrations of $100 \mathrm{ng} / \mathrm{ml}$ and Nifedipine (Sigma, Stockholm, Sweden) in a concentration of $50 \mu \mathrm{M}$ were added to the cultures simultaneously with ATRA. The general caspase inhibitor z-VADfmk $(10 \mu \mathrm{M}$, MP Biomedicals, Doornveld, Belgium) and the calpain inhibitor E-64d (25 $\mu \mathrm{M}$, Sigma, Stockholm, Sweden) were used.

\section{Antibodies and Western blot experiments}

Samples were mixed with Laemmli's loading buffer, boiled for $5 \mathrm{~min}$ and subjected to $15 \%$ SDS-PAGE at $130 \mathrm{~V}$ followed by electroblotting to measurements) cells were collected, spun down and resuspended in 0.5 and $2 \mathrm{ml}$, respectively, of phenol-red-free RPMI medium supplemented with $2 \%$ FCS containing the dyes in the indicated concentrations. After $30 \mathrm{~min}$ incubation at $37^{\circ} \mathrm{C}$ in the dark, the cells were stored on ice and analyzed on a FACScan Flow cytometer (Becton Dickinson, San Jose, CA, USA). Necrotic cells were excluded based on forward and side scatter criteria and data were analyzed using the CellQuest software (Becton Dickinson).

Cells stained with the calcium-sensitive dye Rhod-2 were washed and reincubated for $30 \mathrm{~min}$ in medium without the dye at $37^{\circ} \mathrm{C}$ to reduce cytoplasmic background of the dye. The multivalent cation Rhod-2-AM is accumulated by energized mitochondria according to the mitochondrial membrane potential, hydrolyzed and trapped in the mitochondrial matrix. Measurements of the Rhod-2 fluorescence were performed using a plate reader (Labsystems, Stockholm, Sweden) at $544 \mathrm{~nm}$ excitation and 590 emission wavelengths. To obtain maximum fluorescence $\left(f_{\max }\right)$ cells were sequentially lysed by a detergent, Trition X-100. Minimum fluorescence value $\left(f_{\min }\right)$ was obtained upon addition of the calcium chelator EGTA ( $5 \mathrm{mM}$, final concentration). Intramitochondrial calcium concentrations were calculated using the formula $[\mathrm{Ca}]_{\mathrm{m}}=k_{\mathrm{d}} \times\left(f-f_{\min }\right) /\left(f_{\max }-f\right)$, where $k_{\mathrm{d}}$ (the binding constant) $=570 \mathrm{nM}$ and $f=$ fluorescence. Fluorescence microscopy was used to confirm that the vast majority of Rhod-2 fluorescence was associated with mitochondria.

\section{Caspase assay}

The measurement of DEVD-AMC (Peptide Institute, Osaka, Japan) cleavage was performed using a fluorometric assay. One million cells were sedimented and washed once with PBS. After centrifugation, cells were resuspended in $25 \mu \mathrm{l}$ PBS, added to a microtiter plate and combined with 
the appropriate peptide substrate dissolved in a standard reaction buffer (100 mM HEPES, 10\% sucrose, $5 \mathrm{mM}$ dithiothreitol and $0.1 \% 3-[(3-$ cholamidopropyl) dimethylammonio]-1-propanesulfonate (CHAPS), $\mathrm{pH}$ 7.25). Cleavage of the fluorogenic peptide substrate was monitored by AMC liberation in a Fluoroscan II plate reader (Labsystems, Stockholm, Sweden) using $355 \mathrm{~nm}$ excitation and $460 \mathrm{~nm}$ emission wavelengths. Fluorescence units were converted into the amount of AMC (pmol) using a standard curve generated with free AMC. Data from duplicate samples were then analyzed by linear regression.

\section{Isolation of rat liver mitochondria}

The liver of male Sprague-Dawley rats was minced on ice, resuspended in $50 \mathrm{ml}$ of MSH buffer ( $210 \mathrm{mM}$ mannitol, $70 \mathrm{mM}$ sucrose, $5 \mathrm{mM}$ HEPES, pH 7.5), supplemented with $1 \mathrm{mM}$ EDTA and homogenized with a glass homogenizer and Teflon pestle. Homogenates were centrifuged at $600 \times g$ for $8 \mathrm{~min}$ at $4^{\circ} \mathrm{C}$. The supernatant was decanted and recentrifuged at $5500 \times g$ for $15 \mathrm{~min}$ to form a mitochondrial pellet that was resuspended in MSH buffer without EDTA and centrifuged again at $5500 \times g$ for $15 \mathrm{~min}$. The final mitochondrial pellet was resuspended in MSH buffer at a protein concentration of $80-100 \mathrm{mg} / \mathrm{ml}$.

\section{Measurement of mitochondrial functions}

Isolated rat liver mitochondria $(1 \mathrm{mg})$ or P39 cells $\left(5 \times 10^{6}\right)$ were resuspended in 1 or $0.3 \mathrm{ml}$ of buffer $\left(150 \mathrm{mM} \mathrm{KCl}, 5 \mathrm{mM} \mathrm{KH}_{2} \mathrm{PO}_{4}, 1 \mathrm{mM}\right.$ $\mathrm{MgSO}_{4}, 5 \mathrm{mM}$ Tris, $\mathrm{pH} 7.4$ ), respectively. Measurement of respiration was performed at $30^{\circ} \mathrm{C}$. Cells were permeabilized with $0.005 \%$ digitonin. Succinate $(5 \mathrm{mM})$ in the presence of rotenone $(2 \mu \mathrm{M})$, malate + pyruvate ( $5 \mathrm{mM}$ each) and TMPD $(0.5 \mathrm{mM})+$ ascorbate $(1 \mathrm{mM})$ were used as mitochondrial substrates. Changes in the oxygen concentration were monitored with an oxygen electrode (Hansatech Instruments, Norfolk, UK) and analyzed with the OxygraphPlus software (Hansatech Instruments, Norfolk, UK). ADP and CCCP were used in concentrations of 75 and $0.2 \mu \mathrm{M}$ for the experiments with cells or 200 and $1 \mu \mathrm{M}$ for the experiments with isolated mitochondria, respectively. Isolated mitochondria with an RCR (defined as the rate of respiration in the presence of ADP divided by the rate obtained following the expenditure of ADP) above 3.5 were used for all experiments. Fresh mitochondria were prepared for each experiment and used within $4 \mathrm{~h}$. V4 respiration was measured in mitochondria as the steady-state respiration after expenditure of ADP. In cells, basal V4 respiration was estimated in the presence of $1 \mu \mathrm{M}$ atractyloside, which blocks ADP entry into mitochondria.

For measurement of mitochondrial calcium loading, $1.5 \times 10^{6}$ cells were suspended in $400 \mu$ of buffer $\left(150 \mathrm{mM} \mathrm{KCl}, 5 \mathrm{mM} \mathrm{KH}_{2} \mathrm{PO}_{4}, 5 \mathrm{mM}\right.$ succinate, $1 \mathrm{mM} \mathrm{MgSO}_{4}, 5 \mathrm{mM}$ Tris, $\mathrm{pH}$ 7.4). Cells were permeabilized with $0.005 \%$ digitonin and $2 \mu \mathrm{M}$ rotenone was added in order to maintain pyridine nucleotides in a reduced form. Mitochondrial calcium uptake was induced by sequential additions of calcium to the cells. Calcium concentration changes were registered using a calcium-sensitive electrode (Thermo Orion, Beverly, USA) and visualized with a chart recorder.

\section{Analysis of differentiation}

Differentiation was determined with NBT after stimulation with phorbolmyristate-acetate as described elsewhere. ${ }^{8}$ Briefly, $1 \times 10^{6}$ cells were spun down at $240 \times g$ for $5 \mathrm{~min}$. Cells were resuspended in $20 \%$ FBS in RPMl prewarmed to $37^{\circ} \mathrm{C}$. The cell suspension was mixed with equal volume of NBT working solution (NBT, $1.5 \mathrm{mg} / \mathrm{ml}$ and phorbol-myristate- acetate $400 \mathrm{ng} / \mathrm{ml}$ in PBS) prewarmed to $37^{\circ} \mathrm{C}$, and incubated for $30 \mathrm{~min}$. Cytospins preparation were air-dried, fixed in methanol and counterstained with May-Grünwald-Giemsa. The percentage of cell containing dark blue formazan deposits was counted in a total of 200 cells.

\section{Apoptotic morphology}

Apoptosis was assessed by estimating morphologic features as fragmented nuclei and condensed chromatin in May-Grünwald-Giemsa staining on cytospined slides. The number of apoptotic cells was expressed in percentage of a total (minimum 200) cells counted per slide.

\section{Acknowledgements}

This study was supported by Grants 3689-B01-07XBC (EHL) and 3829B04-09XAC (BZ) from the Swedish Cancer Society, Grants 01:164 (EHL) and 041502 (BZ) from the Stockholm Cancer Society, Grant 31X-0247137A (BZ) from the Swedish Research Council and QLK3-CT-2002-01956 (BZ) from the European Union.

\section{References}

1. Ades L, Chevret S, De Botton S, Thomas X, Dombret H, Beve B, Sanz M, Guerci A, Miguel JS, Dela Serna J, Garo C, Stoppa AM, Reman O, Stamatoulas A, Fey M, Cahn JY, Sotto JJ, Bourhis JH, Parry A, Chomienne C, Degos $L$ and Fenaux P (2004) Outcome of acute promyelocytic leukemia treated with all trans retinoic acid and chemotherapy in elderly patients: the European group experience. Leukemia 19: 230-233

2. Al Bahar S, Pandita R, Bavishi K and Kreze O (2004) All-trans retinoic acid and chemotherapy in the treatment of acute promyelocytic leukemia. Indian $\mathrm{J}$. Cancer 41: 125-128

3. Gupta V, Yi QL, Brandwein J, Lipton JH, Messner HA, Schuh AC, Wells RA and Minden MD (2005) Role of all-trans-retinoic acid (ATRA) in the consolidation therapy of acute promyelocytic leukaemia (APL). Leukemia Res. 29: 113-114

4. Tallmann MS (2004) Curative therapeutic approaches to APL. Ann. Hematol. 83 (Suppl 1): S81-S82

5. Gianni M, Ponzanelli I, Mologni L, Reichert U, Rambaldi A, Terao M and Garattini E (2000) Retinoid-dependent growth inhibition, differentiation and apoptosis in acute promyelocytic leukemia cells. Expression and activation of caspases. Cell Death Differ. 7: 447-460

6. Altucci $\mathrm{L}$ and Gronemeyer $\mathrm{H}$ (2002) Decryption of the retinoid death code in leukemia. J. Clin. Immunol. 22: 117-123

7. Zhang H, Satyamoorthy K, Herlyn M and Rosdahl I (2003) All-trans retinoic acid (atRA) differentially induces apoptosis in matched primary and metastatic melanoma cells - a speculation on damage effect of atRA via mitochondrial dysfunction and cell cycle redistribution. Carcinogenesis 24: 185-191

8. Hassan Z, Fadeel B, Zhivotovsky B and Hellstrom-Lindberg E (1999) Two pathways of apoptosis induced with all-trans retinoic acid and etoposide in the myeloid cell line P39. Exp. Hematol. 27: 1322-1329

9. Altucci $L$ and Gronemeyer $H$ (2001) Nuclear receptors in cell life and death. Trends Endocrinol. Metab. 12: 460-468

10. Doyle BT, O'Neill AJ, Fitzpatrick JM and Watson RW (2004) Differentiationinduced HL-60 cell apoptosis: a mechanism independent of mitochondrial disruption? Apoptosis 9: 345-352

11. Otake $Y$, Sengupta TK, Bandyopadhyay S, Spicer EK and Fernandes DJ (2004) Drug-induced destabilization of bcl-2 mRNA: a new approach for inducing apoptosis in tumor cells. Curr. Opin. Invest. Drugs 5: 616-622

12. Otake Y, Sengupta TK, Bandyopadhyay S, Spicer EK and Fernandes DJ (2005) Retinoid-induced apoptosis in $\mathrm{HL}-60$ cells is associated with nucleolin down-regulation and destabilization of Bcl-2 mRNA. Mol. Pharmacol. 67: 319-326

13. Pettersson F, Dalgleish AG, Bissonnette RP and Colston KW (2002) Retinoids cause apoptosis in pancreatic cancer cells via activation of RAR-gamma and altered expression of Bcl-2/Bax. Br. J. Cancer 87: 555-561 
14. Rigobello MP, Scutari G, Friso A, Barzon E, Artusi S and Bindoli A (1999) Mitochondrial permeability transition and release of cytochrome $c$ induced by retinoic acids. Biochem. Pharmacol. 58: 665-670

15. Notario B, Zamora M, Vinas $O$ and Mampel T (2003) All-trans-retinoic acid binds to and inhibits adenine nucleotide translocase and induces mitochondrial permeability transition. Mol. Pharmacol. 63: 224-231

16. Maianski NA, Mul FP, van Buul JD, Roos D and Kuijpers TW (2002) Granulocyte colony-stimulating factor inhibits the mitochondria-dependent activation of caspase-3 in neutrophils. Blood 99: 672-679

17. Maianski NA, Roos D and Kuijpers TW (2004) Bid truncation, bid/bax targeting to the mitochondria, and caspase activation associated with neutrophil apoptosis are inhibited by granulocyte colony-stimulating factor. J. Immunol. 172: 7024-7030

18. Carlsson G, Aprikyan AA, Tehranchi R, Dale DC, Porwit A, Hellstrom-Lindberg E, Palmblad J, Henter JI and Fadeel B (2004) Kostmann syndrome: severe congenital neutropenia associated with defective expression of Bcl-2, constitutive mitochondrial release of cytochrome $c$, and excessive apoptosis of myeloid progenitor cells. Blood 103: 3355-3361

19. Hellstrom-Lindberg E, Gulbrandsen N, Lindberg G, Ahlgren T, Dahl IM, Dybedal I, Grimfors G, Hesse-Sundin E, Hjorth M, Kanter-Lewensohn L, Linder O, Luthman M, Lofvenberg E, Oberg G, Porwit-MacDonald A, Radlund A, Samuelsson J, Tangen JM, Winquist I and Wisloff $F$ (2003) A validated decision model for treating the anaemia of myelodysplastic syndromes with erythropoietin+granulocyte colony-stimulating factor: significant effects on quality of life. Br. J. Haematol. 120: 1037-1046

20. Hellstrom-Lindberg E, Ahlgren T, Beguin Y, Carlsson M, Carneskog J, Dahl IM, Dybedal I, Grimfors G, Kanter-Lewensohn L, Linder O, Luthman M, Lofvenberg E, Nilsson-Ehle H, Samuelsson J, Tangen JM, Winqvist I, Oberg G, Osterborg A and Ost A (1998) Treatment of anemia in myelodysplastic syndromes with granulocyte colony-stimulating factor plus erythropoietin: results from a randomized phase II study and long-term follow-up of 71 patients. Blood 92: 68-75

21. Hellstrom-Lindberg E, Kanter-Lewensohn L and Ost A (1997) Morphological changes and apoptosis in bone marrow from patients with myelodysplastic syndromes treated with granulocyte-CSF and erythropoietin. Leukemia Res. 21: 415-425

22. Tehranchi $R$, Fadeel $B$, Forsblom AM, Christensson B, Samuelsson J, Zhivotovsky B and Hellstrom-Lindberg E (2003) Granulocyte colony-stimulating factor inhibits spontaneous cytochrome $c$ release and mitochondria-dependent apoptosis of myelodysplastic syndrome hematopoietic progenitors. Blood 101: 1080-1086

23. Schmidt-Mende J, Tehranchi R, Forsblom AM, Joseph B, Christensson B, Fadeel B, Zhivotovsky B and Hellstrom-Lindberg E (2001) Granulocyte colonystimulating factor inhibits Fas-triggered apoptosis in bone marrow cells isolated from patients with refractory anemia with ringed sideroblasts. Leukemia 15: 742-751

24. Launay S, Gianni M, Diomede L, Machesky LM, Enouf J and Papp B (2003) Enhancement of ATRA-induced cell differentiation by inhibition of calcium accumulation into the endoplasmic reticulum: cross-talk between RAR alpha and calcium-dependent signaling. Blood 101: 3220-3228

25. Chapekar MS, Hartman KD, Knode MC and Glazer RI (1987) Synergistic effect of retinoic acid and calcium ionophore A23187 on differentiation, c-myc expression, and membrane tyrosine kinase activity in human promyelocytic leukemia cell line HL-60. Mol. Pharmacol. 31: 140-145

26. Munaron L, Antoniotti S and Lovisolo D (2004) Intracellular calcium signals and control of cell proliferation: how many mechanisms? J. Cell. Mol. Med. 8: $161-168$

27. Parekh $A B$ (2003) Mitochondrial regulation of intracellular $\mathrm{Ca}^{2+}$ signaling: more than just simple $\mathrm{Ca}^{2+}$ buffers. News Physiol. Sci. 18: 252-256

28. Mehta K and Cheema S (1999) Retinoid-mediated signaling pathways in CD38 antigen expression in myeloid leukemia cells. Leukemia Lymphoma 32: $441-449$

29. Orrenius $S$, Zhivotovsky B and Nicotera $P$ (2003) Regulation of cell death: the calcium-apoptosis link. Nat. Rev. Mol. Cell. Biol. 4: 552-565

30. Wood DE and Newcomb EW (1999) Caspase-dependent activation of calpain during drug-induced apoptosis. J. Biol. Chem. 274: 8309-8315

31. Wood DE, Thomas A, Devi LA, Berman Y, Beavis RC, Reed JC and Newcomb EW (1998) Bax cleavage is mediated by calpain during drug-induced apoptosis. Oncogene 17: 1069-1078

32. Crompton M (1999) The mitochondrial permeability transition pore and its role in cell death. Biochem. J. 341 (Part 2): 233-249

33. Saelens $X$, Festiens $N$, Vande Walle $L$, van Gurp $M$, van Loo $G$ and Vandenabeele $P(2004)$ Toxic proteins released from mitochondria in cell death. Oncogene 23: 2861-2874

34. Gogvadze V, Robertson JD, Zhivotovsky B and Orrenius S (2001) Cytochrome $c$ release occurs via $\mathrm{Ca}^{2+}$-dependent and $\mathrm{Ca}^{2+}$-independent mechanisms that are regulated by Bax. J. Biol. Chem. 276: 19066-19071

35. Fernandez-Gomez FJ, Galindo MF, Gomez-Lazaro M, Yuste VJ, Comella JX, Aguirre $\mathrm{N}$ and Jordan J (2005) Malonate induces cell death via mitochondrial potential collapse and delayed swelling through an ROS-dependent pathway. Br. J. Pharmacol. 144: 528-537

36. Murphy RC, Schneider E and Kinnally KW (2001) Overexpression of Bcl-2 suppresses the calcium activation of a mitochondrial megachannel. FEBS Lett. 497: 73-76

37. Gao G and Dou QP (2000) N-terminal cleavage of bax by calpain generates a potent proapoptotic $18-\mathrm{kDa}$ fragment that promotes bcl-2-independent cytochrome $C$ release and apoptotic cell death. J. Cell. Biochem. 80: 53-72

38. Matsui W, Smith BD, Vala M, Beal N, Huff CA, Diehl LF and Jones RJ (2005) Requirement for myeloid growth factors in the differentiation of acute promyelocytic leukaemia. Br. J. Haematol. 128: 853-862

39. Higuchi T, Kizaki M and Omine M (2004) Induction of differentiation of retinoic acid-resistant acute promyelocytic leukemia cells by the combination of all-trans retinoic acid and granulocyte colony-stimulating factor. Leukemia Res. 28: $525-532$

40. Newcomer ME (1995) Retinoid-binding proteins: structural determinants important for function. FASEB J. 9: 229-239 